\title{
A multidisciplinary approach to therapeutic risk management of the suicidal patient
}

\author{
This article was published in the following Dove Press journal: \\ Journal of Multidisciplinary Healthcare \\ 24 June 2015 \\ Number of times this article has been viewed
}

\section{Cynthia L Grant ${ }^{1,2}$ \\ Jaimie L Lusk ${ }^{3}$}

'Arapahoe/Douglas Mental Health Network, Englewood, CO, ${ }^{2}$ School of Education and Human Development, University of Colorado Denver, Denver, CO, ${ }^{3}$ Mental Health Service, VA Portland Health Care System, Portland, OR, USA
Correspondence: Cynthia L Grant Arapahoe/Douglas Mental Health Network, 155 Inverness Dr West, Englewood, CO 80II2, USA Email cgrant@admhn.org
Abstract: As health care trends toward a system of care approach, providers from various disciplines strive to collaborate to provide optimal care for their patients. While a multidisciplinary approach to suicide risk assessment and management has been identified as important for reducing suicidality, standardized clinical guidelines for such an approach do not yet exist. In this article, the authors propose the adoption of the therapeutic risk management of the suicidal patient (TRMSP) to improve suicide risk assessment and management within multidisciplinary systems of care. The TRMSP, which has been fully articulated in previous articles, involves augmenting clinical risk assessment with structured instruments, stratifying risk in terms of both severity and temporality, and developing and documenting a safety plan. Augmenting clinical risk assessments with reliable and valid structured instruments serves several functions, including ensuring important aspects of suicide are addressed, establishing a baseline for suicidal thoughts and behaviors, facilitating interprofessional communication, and mitigating risk. Similarly, a twodimensional risk stratification qualifying suicide risk in terms of both severity and temporality can enhance communication across providers and settings and improve understanding of acute crises in the context of chronic risk. Finally, safety planning interventions allow providers and patients to collaboratively create a personally meaningful plan for managing a suicidal crisis that can be continually modified across time with multiple providers in different care settings. In a busy care environment, the TRMSP can provide concrete guidance on conducting clinically and medicolegally sound suicide risk assessment and management. This collaborative and comprehensive process would potentially improve care of patients with suicidality, optimize clinical resources, decrease unnecessary and costly admissions, and mitigate medicolegal risk. The TRMSP may serve as a foundation for building a standardized, collaborative, stepped-care approach that patients, individual providers, and the health care system can all benefit from.

Keywords: suicide risk assessment, multidisciplinary, systems of care

\section{Introduction}

Providing care for patients at risk for suicide is best accomplished collaboratively with cooperation of professionals across health care disciplines and settings. Given that all health care professionals may encounter patients at risk for suicide in their clinical work, collaborative suicide risk management is relevant to a variety of providers and health care settings. A multidisciplinary process transcends silos in care, facilitating fluid risk assessment and management. Consistent with this approach, Simon and Gutheil penned the phrase, "never worry alone", ${ }^{1}$ to emphasize the importance of a multidisciplinary approach to suicide.

Therapeutic risk management of the suicidal patient (TRMSP) ${ }^{2}$ is an approach for working with patients at risk for suicide that was devised by clinicians and researchers 
at the Rocky Mountain Mental Illness Research, Education and Clinical Center in Denver, CO, USA based on clinicallegal concepts described by Simon and Shuman. ${ }^{3}$ Therapeutic risk management ensures that the role and competence of the clinician is aligned with legal concerns surrounding suicide risk in psychiatric practice. ${ }^{3}$ The TRMSP model involves a three-tiered approach to managing a patient at risk for suicide, which includes the use of objective measures in risk assessment, acute and chronic risk stratification, and safety planning. This model, which has been fully articulated elsewhere, ${ }^{2,4-6}$ was originally described for use by individual practitioners in psychiatry. The current paper discusses how the model can be applied to multidisciplinary health care. Systems of care may strategically deploy multidisciplinary assets to apply the TRMSP model in a manner that enhances patient treatment and safety, is medicolegally sound, and optimizes limited and valuable clinical resources. Readers are referred to the original publications describing each component for detailed descriptions and theoretical underpinnings.

\section{The value of a multidisciplinary approach to TRMSP}

The National Institute of Health defines multidisciplinary care as an approach to health care that brings individual disciplines together to address a common problem. ${ }^{7}$ One well-documented benefit of a multidisciplinary approach to health care is that it ensures that all bio-psycho-socialcultural aspects of care are provided. ${ }^{8}$ While a system of care approach is not a new concept to health care, ${ }^{9-11}$ it has not been explicitly applied to TRMSP. As suicide risk has bio-psycho-social-cultural components, ${ }^{12}$ systems of care can utilize a multidisciplinary approach to provide comprehensive assessment and management of individuals at risk for suicide. All providers involved should share a commitment to prioritize suicide risk assessment, an appreciation for each discipline's contributions to patient care, and an awareness of the interdependency of practice. ${ }^{13}$

In addition to providing comprehensive care, multidisciplinary approaches offer an opportunity to ensure care is delivered in ways that optimize patient safety and minimize liability for both the system of care and the individual providers comprising it. The TRMSP approach permits systems of care to share responsibility for the treatment of patients at risk for suicide and allows providers to incorporate the totality of available clinical data. This in turn diffuses risk management of high-risk patients, thereby mitigating anxiety at the individual provider level, minimizing defensive practices born of anxiety, and facilitating optimal clinical decision-making.

Despite its importance, there exists a paucity of both research and clinical guidelines to multidisciplinary suicide risk assessment and management. In a seminal text of suicidology, Maris et al wrote, "While suicidologists give lip service to the multidisciplinary study of suicide, in actual fact most of us have very narrow and specialized domain assumption - usually those related to our professional training and subdisciplinary paradigms". ${ }^{14}$ That said, the Department of Health and Human Services at the National Institute of Mental Health recommends collaborative care as a best practice for reducing suicidality. ${ }^{15}$ They describe a model in which a nurse, social worker, or other appropriately trained staff obtains information about suicide risk via screening, which then facilitates an initial treatment plan and follow-up care. This can be followed by consultation with a mental health professional such as a psychiatrist who serves an advisory role to primary care teams. The strength of this stepped-care approach is in its maximization of the effectiveness of collaborative care, with the aim of cost-effectiveness in mind by starting with low-intensity interventions that may progress to more intensive interventions.

\section{Multidisciplinary approach to TRMSP in primary care, the emergency department, and mental health}

The value in adopting the TRMSP approach is not only to combat the propensity to worry alone, as Simon and Gutheil noted, ${ }^{1}$ but also to utilize the various strengths that multidisciplinary team members bring, since not every provider will be able (due to training and/or time constraints) to carry out all the components of TRMSP. Ultimately, it is our belief that providers in the settings of primary care, the emergency department (ED), and mental health outpatient can offer a unique perspective that will collectively result in a clearer picture of suicide risk, which can subsequently facilitate a better risk management plan. Figure 1 displays the interconnectedness of the system of care approach to TRMSP as an alternative to each discipline operating as a silo.

The majority of mental health care in the United States is provided in outpatient primary care settings by non-psychiatrist physicians and nurse practitioners. ${ }^{16,17}$ Additionally, between $75 \%$ and $90 \%$ of individuals who die by suicide had contact with a primary care provider in 90 days preceding their death. ${ }^{18,19}$ Physician education related to screening for mental health issues has been identified as a primary 


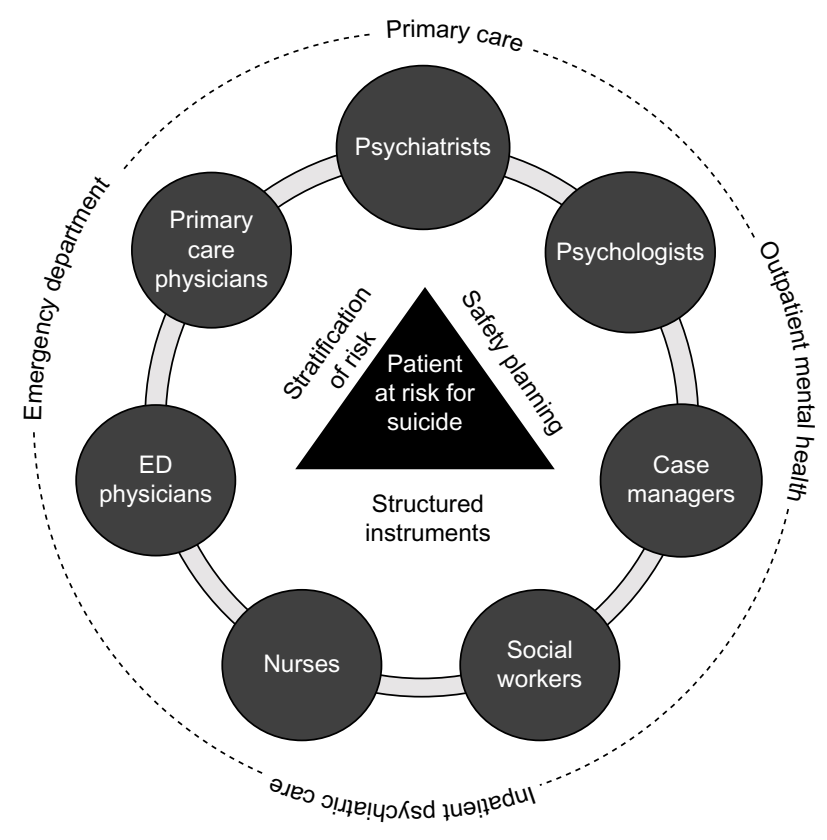

Figure I Multidisciplinary use of TRMSP.

Abbreviations: ED, emergency department; TRMSP, therapeutic risk management of the suicidal patient.

method to prevent suicide, ${ }^{20}$ yet licensing and accrediting bodies have not recognized specific tools or procedures for assessment or management of suicide risk in primary care settings. ${ }^{21}$ Similarly, there is little formal education regarding suicide risk assessment in nursing programs both in the United States or internationally, ${ }^{22,23}$ with evidence suggesting that neither primary care physicians ${ }^{24,25}$ nor nurse ${ }^{26}$ are well prepared to assess and treat a person who is at risk for suicide.

EDs are often used as an important safety net for persons at risk for suicide in the community, often bridging the gap between outpatient services and inpatient settings. There are approximately 3.7 million ED visits in the United States each year for suicides or suicide attempts, a number that comprises nearly $7 \%$ of all ED visits. ${ }^{27}$ EDs typically employ physicians, nurses, and social workers. Such providers report some confidence in screening for suicide risk. ${ }^{28}$ The purpose of a screening is to evaluate the possible presence of suicide risk to determine if a person needs assessment. Screening for suicide risk involves asking specific questions designed to determine whether a more detailed evaluation is needed. However, once screening for suicide risk has occurred, demands on provider time and limited resources are frequently a barrier to more thorough suicide risk assessment and management in a high-volume ED setting. ${ }^{28}$ The assessment process, involving defining the scope of a problem and recommending treatment interventions to address the problem, remains highly variable across practice settings. ${ }^{29,30}$
In addition to professionals working in traditional medical settings, mental health systems could benefit from a concrete roadmap delineating a clinically and medicolegally sound process for suicide risk assessment and management. Training in suicide risk assessment is a core competency requirement in psychiatric residency and for other providers employed in mental health settings. In the United States, there is a recent push for state legislation to require qualified professionals in primary care, $\mathrm{ED}$, and mental health settings to complete training in suicide risk assessment, treatment, and management. ${ }^{31}$ However, psychiatrists consistently report the need for increased training on the care of patients who are suicidal. ${ }^{32-34}$ Furthermore, while multidisciplinary mental health practitioners (eg, social workers, psychologists, case managers, counselors, psychiatrists, and psychiatric nurses) are often trained in suicide prevention and intervention techniques, many have not been provided with the specific training and/or experience to adequately apply such knowledge to clinical practice. This can become particularly challenging in acute crises wherein the anxiety attendant in working with a suicidal patient and making difficult clinical calls - as well as fear regarding potential medicolegal consequences stemming from poor outcomes - may interfere with optimal skill deployment.

Individual providers have their own beliefs, theoretical orientations, and limited resources related to suicide risk assessments, many of which do not optimally align with the complex needs of the patient at risk for suicide. ${ }^{35}$ In some cases, the electronic health record in use at a particular setting dictates the suicide screening and assessment tools to be used. Yet systems of care can strive to correct for idiosyncratic individual practices or the limited suicide risk tools available at a practice location. A multidisciplinary approach aims to offer sound clinical care and cogent risk management practices by drawing on resources from a network of providers.

\section{Implementing TRMSP as a multidisciplinary process Structured instruments}

All patients entering into a system of care should be screened for mental illness and suicide risk. Patients who present at risk for suicide will require additional suicide risk assessment. One strategy for risk assessment involves the use of formal self-report measures. ${ }^{36}$ Providers across disciplines often experience disdain for the use of structured instruments, favoring their own personalized clinical interview. ${ }^{37}$ However, vital information regarding suicide risk may be missed during the course of an unstructured clinical interview. This potential 
may be minimized when reliable and valid structured tools or self-report measures are used as supplements to the clinical interview. Examples of suicide-specific structured instruments include the Columbia Suicide Severity Rating Scale (C-SSRS), ${ }^{38}$ Beck Scale for Suicide Ideation (BSS), ${ }^{39}$ the Beck Hopelessness Scale (BHS), ${ }^{40}$ and the Reasons for Living Inventory (RFL). ${ }^{41}$

The use of structured instruments offers several potential advantages to a system of care. First, standardized use of suicide risk assessment measures helps establish consistent documentation, communication, tracking, and standards of care across treatment settings and disciplines, facilitating informed care, regardless of how familiar a provider may be with a patient. Second, such tools can be deployed by a wide array of clinicians. There are very few restrictions by discipline associated with the administration of the C-SSRS, the $\mathrm{BSS}$, the BHS, or the RFL; each is relatively easy and takes little time to administer. Furthermore, use of these measures will help standardize statements regarding risk, as providers may have widely different experiences and knowledge of suicide risk assessment. Also, the use of structured instruments in primary care or ED settings may allow for providers who are less comfortable directly asking about suicidal thoughts or behaviors to begin a conversation with a patient.

Finally, the use of structured instruments can improve documentation, all while saving costly higher level provider time. For instance, intake personnel might administer structured instruments or self-report measures, the results of which would then be available for review by higher-level clinicians for incorporation into their formulations regarding the level of risk. Such a process might simultaneously yield more robust and nuanced risk assessments, while minimizing the chance of omitting important inquiries.

One disadvantage to using structured instruments in a system of care is the need for caution among practitioners who rely solely on numerical results generated by structured instruments to determine suicide risk. While the C-SSRS is an especially rich tool that offers descriptive detail about ideation, attempts, and behaviors that can be used qualitatively, this is less the case with the numerical scores generated by the BSS, the BHS, or the RFL. Interpreting a number out of context is too simplistic a response for a highly complex, volatile situation. Therefore, it is important for providers using structured instruments to receive training in assessment and develop a keen understanding of how to interpret results in the context of other qualitative, subjective, and historical information about a patient. For example, an ED social worker with some assessment background who administers the BSS might identify suicidal ideation and risk at baseline levels based upon similar responses to the same instrument during mental health sessions in the preceding weeks. However, for this patient, comparison with a baseline score might reveal significant elevation in suicide risk.

When combined with clinical risk assessment, the incorporation of suicide-specific structured instruments offers a nuanced approach to suicide risk assessment, with risk assessment as a process as opposed to an event. Importantly, structured assessment tools must be met with great clinical understanding within a system of care to avoid unnecessary and costly admissions, while also minimizing the chance that an acute crisis requiring hospitalization goes missed. From the medicolegal perspective, these instruments can and should populate the medical record, but must be balanced with individualized narratives of the patient's situation.

\section{Stratification of risk by severity and temporality}

Risk assessment is intended to guide formulations regarding the level of suicide risk. Therapeutic risk assessment of the suicidal patient requires moving beyond a one-dimensional stratification of suicide risk that has traditionally been predicated upon terms such as low, moderate, or high.,42 Such one-dimensional formulations (and documentation) fail to capture the dynamic nature of suicidal ideation. Poor communication between providers spanning different treatment settings is likely to result, and may create untenable medicolegal risk in the unfortunate event of a patient's death by suicide or suicide attempt.

For example, an outpatient psychiatrist might designate his or her patient to be at low risk for suicide, thereby justifying the appropriateness of continued outpatient care and the lack of requirement for admission. But what if that patient actually carries numerous risk factors for suicide and frequently becomes acutely suicidal in the face of psychosocial stressors? Might that low risk designation mislead another provider - especially a non-mental health clinician - who subsequently encounters the patient during crisis? Such a provider might underappreciate the patient's actual risk for suicide. A two-dimensional designation of risk, addressing both acute and chronic risk, can circumvent clinical documentation dilemmas and enhance communications across providers and settings. In this example, the psychiatrist should designate the patient as of low acute risk and high chronic risk, thereby offering a more nuanced and accurate depiction of suicide risk that better communicates the risk and safety needs to other providers. The low acute designation 
justifies the decision to continue care on an outpatient basis. The high chronic designation reflects the patient's tendency to become acutely suicidal in the face of distressing life circumstances, the occurrence of which is difficult to predict. The high chronic designation more effectively communicates this circumstance to other evaluators, indicating a need for routine suicide risk assessment and substantial potential for future self-directed violent behaviors.

Ideally, the language used to describe risk should be uniform so that providers across disciplines and treatment settings may accurately discern the meaning of one another's risk formulations. Hence, a multidisciplinary approach to TRMSP requires a standardized nomenclature that facilitates consistent documentation and communication between providers and creates a cohesive medical record. Table 1 provides suggested criteria to guide each level of stratification in this two-dimensional scheme, based directly on the work of Wortzel et al. ${ }^{5}$

\section{Safety planning}

The third component of the TRMSP model involves the safety planning intervention (SPI). Historically, many providers have been taught to use no-suicide contracts with their patients. ${ }^{43,44}$ These contracts are meant to formalize and document an agreement between a provider and a patient that the patient has agreed not to harm himself or herself. However, there is no empirical support for the effectiveness of no-suicide contracts, ${ }^{45,46}$ and the document offers no legal protection from malpractice claims.$^{47}$ In a system of care spanning providers from various disciplines, the presence of such a contract might inadvertently diminish the collective level of vigilance required to maintain the ongoing risk assessment process that optimizes safety for high-risk individuals.

The SPI is an alternative approach to no-suicide contracts developed by Stanley and Brown that is rooted in empirically supported treatments and suicide prevention theory. ${ }^{48}$ The SPI has been identified as the best practice by the Suicide Prevention Resource Center/American Foundation for Suicide Prevention. ${ }^{49}$ It is a collaborative tool, mutually developed by both patient and provider, and is based upon the most up-todate content obtained from a patient during risk assessment. The safety plan consists of six steps derived from the Safety Plan Treatment Manual to Reduce Suicide Risk. ${ }^{50}$ Table 2 outlines the rationale and instructions for each step.

Just as suicide risk assessment is an ongoing process, so is the SPI; a safety plan should be a living document that is regularly updated to reflect changes in the individual patient's circumstances. ${ }^{6}$ Safety plans are the property of the patient,
Table I Stratified suicide risk assessment

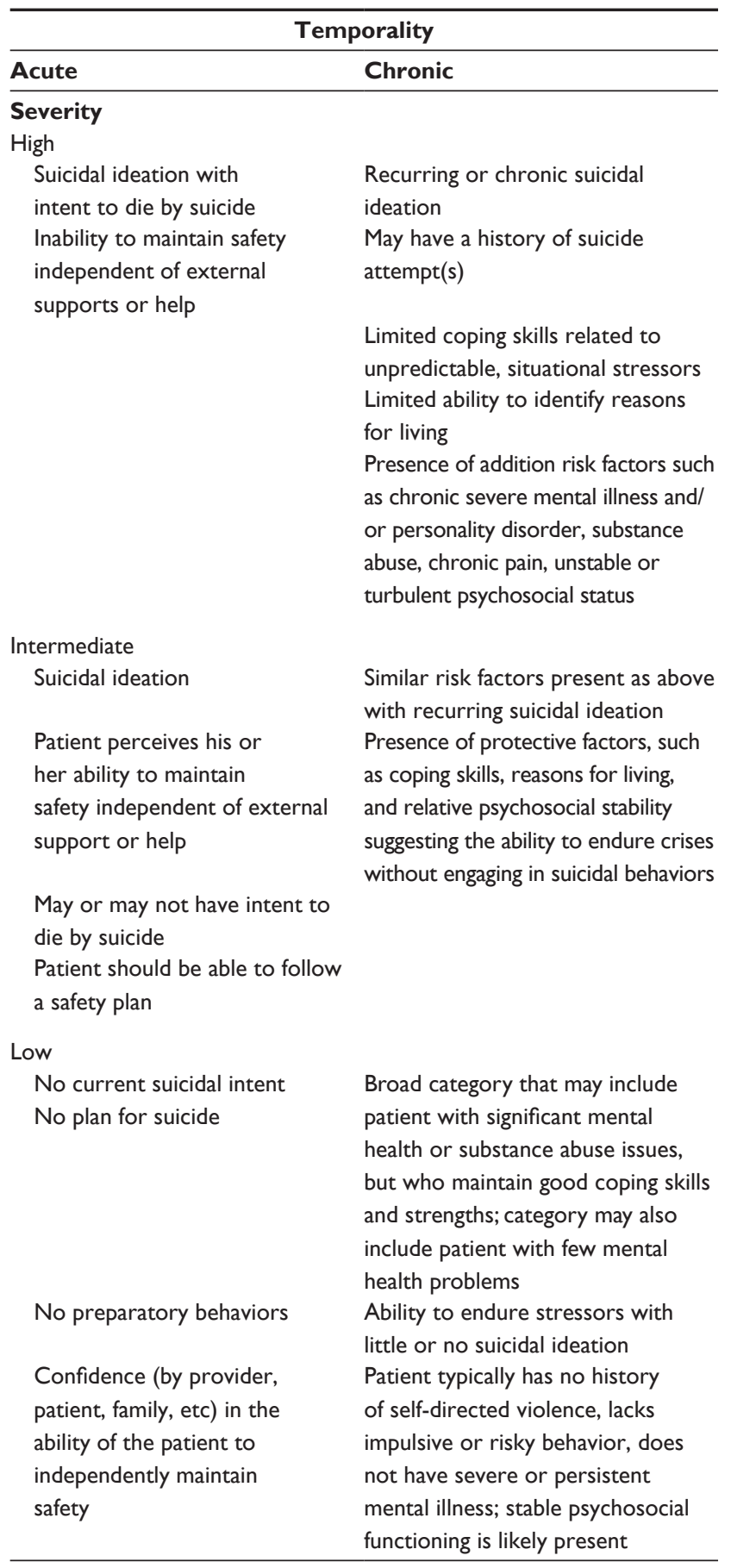

Note: Data from Wortzel et al. ${ }^{5}$

but should be visible to all providers within the network of care so that they can be reinforced across treatment settings and enacted in the event of a suicidal crisis. Utilizing the same SPI at each point of contact within the system of care may allow a cohesive and collaborative approach to caring for these patients. Such shared implementation and reinforcement of the SPI may help systems of care achieve TRMSP in a manner that is, at present, seldom realized. 
Table 2 Safety planning intervention

\begin{tabular}{|c|c|c|}
\hline SPI steps & Rationale & Application \\
\hline Introduction of the plan & $\begin{array}{l}\text { Explain rationale for developing a safety plan to the } \\
\text { patient }\end{array}$ & $\begin{array}{l}\text { Provider conveys compassionate interest in helping } \\
\text { the patient cope with suicidal thoughts }\end{array}$ \\
\hline Step I: Warning signs & $\begin{array}{l}\text { Identify person-specific suicide warning signs in the } \\
\text { patient's own words }\end{array}$ & $\begin{array}{l}\text { Provider advises patient to use the next steps in the } \\
\text { safety plan when he or she recognizes warning signs }\end{array}$ \\
\hline Step 2: Internal coping strategies & $\begin{array}{l}\text { Patient lists coping strategies that can be used to } \\
\text { distract him/her from the suicide crisis without } \\
\text { the help of another person }\end{array}$ & $\begin{array}{l}\text { Provider can prompt patient to identity strategies } \\
\text { that have worked in the past } \\
\text { Provider should ensure that coping strategies are } \\
\text { individualized and specific }\end{array}$ \\
\hline $\begin{array}{l}\text { Step 3: People and social settings } \\
\text { that provide distraction }\end{array}$ & $\begin{array}{l}\text { Patient lists individuals who he or she can reach } \\
\text { out to for the purpose of distracting from the } \\
\text { suicide crisis }\end{array}$ & $\begin{array}{l}\text { Provider encourages patient to increase his or her } \\
\text { social connection }\end{array}$ \\
\hline $\begin{array}{l}\text { Step 4: People whom I can ask } \\
\text { for help }\end{array}$ & $\begin{array}{l}\text { Patient identifies who he or she can contact and } \\
\text { be notified of crisis }\end{array}$ & $\begin{array}{l}\text { Provider and patient agree on personal contacts } \\
\text { whom the patient can reach out to engage in help- } \\
\text { seeking behaviors }\end{array}$ \\
\hline $\begin{array}{l}\text { Step 5: Professionals and agencies } \\
\text { I can contact during a crisis }\end{array}$ & $\begin{array}{l}\text { Patient identifies professionals and emergency } \\
\text { resources that he or she can contact in the event } \\
\text { that previous steps do not resolve the suicide crisis }\end{array}$ & $\begin{array}{l}\text { Provider should discuss what to expect when } \\
\text { patient contacts these resources (eg, conditions that } \\
\text { may warrant emergency mental health intervention) }\end{array}$ \\
\hline $\begin{array}{l}\text { Step 6: Making the environment } \\
\text { safe }\end{array}$ & $\begin{array}{l}\text { Patient should remove or restrict access to } \\
\text { weapon or other lethal means in his or her } \\
\text { environment }\end{array}$ & $\begin{array}{l}\text { Provider can offer gun locks to secure weapons } \\
\text { or medication drop off information to dispose of } \\
\text { excess medication } \\
\text { Provider should help patient identify reminders of } \\
\text { reasons for living that can be emphasized in the } \\
\text { home (eg, pictures of family members posted on the } \\
\text { refrigerator) }\end{array}$ \\
\hline
\end{tabular}

\section{Conclusion}

The multidisciplinary systems approach addresses economic realities of health care systems, enabling components of TRMSP to be shifted toward less costly provider time by expanding their use beyond psychiatry. Simultaneously, providers work in concert to collectively yield comprehensive TRMSP. While each member of the multidisciplinary team may have specific roles in the assessment/treatment process, the ability of team members to overlap and reinforce TRMSP tenants across the system of care enhances safety and hopefully improves outcomes. Finally, a multidisciplinary systems approach to TRMSP (documented in the medical record wherein collaboration is apparent) should yield cohesive care, offering emotional and medicolegal comfort to providers and systems of care in the unfortunate event of a poor outcome.

Perhaps, the lack of progress reducing morbidity and mortality from suicide stems in part from an ongoing tendency to pass the baton of responsibility as quickly as possible as suicidal individuals move across treatment settings. Multidisciplinary TRMSP affords the opportunity to reinvent this process as one whereby providers spanning professions and settings collectively and collaboratively share responsibility within the patient's system of care. It is neither in patients' nor providers' best interest to approach the management of suicidal patients as one that should be passed to a different silo within the system. Instead, we need a system that encourages cooperative engagement by providers across disciplines and treatment settings, sharing clinical information, responsibility, and medicolegal risk.

In creating the multidisciplinary approach to TRMSP for systems of care, the goal will be to surround suicidal patients with a network of providers who cooperatively optimize care and mitigate risk as shown in Figure 1. A multidisciplinary approach to TRMSP for systems of care will potentially yield better medical care and enhance patient safety and more sound medicolegal practices. Patients, individual providers, and the health care system all stand to benefit from this collective process. The model offered herein may serve as a foundation for implementing a collaborative process between and across disciplines and treatment settings constituting a network of care.

\section{Disclosure}

The views and opinions expressed in this article are those of the authors and do not necessarily reflect the official policy, position, or views of the Department of Veterans Affairs or the US government. The authors declare no conflicts of interest.

\section{References}

1. Simon R, Gutheil T. Sudden improvement among high-risk suicidal patients: should it be trusted? Psychiatr Serv. 2009;60(3):387-389. 
2. Wortzel HS, Matarazzo B, Homaifar B. A model for therapeutic risk management. J Psychiatr Pract. 2013;19(4):323-326.

3. Simon RI, Shuman DE. Therapeutic risk management of clinical-legal dilemmas: should it be a core competency? J Am Acad Psychiatry Law. 2007;37:155-161.

4. Homaifar B, Matarazzo B, Wortzel HS. Therapeutic risk management of the suicidal patient: augmenting clinical suicide risk assessment with structured instruments. J Psychiatr Pract. 2013;19(5): 406-409.

5. Wortzel HS, Homaifar B, Matarazzo B, Brenner L. Therapeutic risk management of the suicidal patient: stratifying risk in terms of severity and temporality. J Psychiatr Pract. 2014;20(1):63-67.

6. Matarazzo B, Homaifar B, Wortzel HS. Therapeutic risk management of the suicidal patient: safety planning. J Psychiatr Pract. 2014;20(3): 220-224.

7. Rosenfield P. The potential of transdisciplinary research for sustaining and extending linkages between the health and social sciences. Soc Sci Med. 1992;35:1343-1357.

8. Mental Health Commission. Multidisciplinary Team Working: From Theory to Practice. Dublin: St Martin's House; 2006.

9. Vaughn S, Reynolds W, Cope N. Systems of care. In: Silver J, McAllister T, Yudofsky S, editors. The Textbook of Traumatic Brain Injury. 2nd ed. Arlington: American Psychiatric Publishing; 2011:505-520.

10. Pronovost PJ, Bo-Linn GW. Preventing patient harms through systems of care. JAMA. 2012;308(8):769-770.

11. Nichol G, Aufderheide TP, Eigel B, et al; American Heart Association Emergency Cardiovascular Care Committee; Council on Arteriosclerosis, Thrombosis, and Vascular Biology; Council on Cardiopulmonary, Critical Care, Perioperative and Resuscitation; Council on Cardiovascular Nursing; Council on Clinical Cardiology; Advocacy Committee; Council on Quality of Care and Outcomes Research. Regional systems of care for out-of-hospital cardiac arrest a policy statement from the American Heart Association. Circulation. 2010;121(5):709-729.

12. Bertolote J, Fleischmann A, De Leo D, Wasserman D. Psychiatric diagnoses and suicide: revisiting the evidence. Crisis. 2004;25(4):147-155.

13. Orchard C, Curran V, Kabene S. Creating a culture for interdisciplinary collaborative professional practice. Med Educ Online [serial on the Internet]. 2009;10:13. Available from: http://med-ed-online.net/index. php/meo/article/view/4387. Accessed December 13, 2014.

14. Maris RW, Berman AL, Silverman MM. Comprehensive Textbook of Suicidology. New York: The Guildford Press; 2000.

15. Schoenbaum M, Heinssen R, Pearson J. Opportunities to Improve Interventions to Reduce Suicidality: Civilian "Best Practices" for Army Consideration. Bethesda: National Institute of Mental Health; 2009.

16. Olfson M, Blanco C, Wang S, Laje G, Correll CU. National trends in the mental health care of children, adolescents, and adults by officebased physicians. JAMA Psychiatry. 2014;71(1):81-90.

17. Morgan P, Everett C, Hing E. Nurse practitioners, physician assistants, and physicians in community health centers, 2006-2010. Healthcare. 2014. Available from: http://dx.doi.org/10.1016/j.hjdsi.2014.06.002

18. DeLeo D, Draper B, Snowdon J, Kolves K. Contacts with health professionals before suicide: missed opportunities for prevention. Compr Psychiatry. 2013;54(7):1117-1123.

19. Feldman MD, Franks P, Duberstein PR, Vannoy S, Epstein R, Kravitz RL. Let's not talk about it: suicide inquiry in primary care. Ann Fam Med. 2007;5(5):412-418.

20. Mann JJ, Apter A, Bertolote J, et al. Suicide prevention strategies: a systematic review. JAMA. 2005;294(16):2064-2074.

21. Gaynes BN, West SL, Ford CA, Frame P, Klein J, Lohr KN. Screening for suicide risk in adults: a summary of the evidence for the US Preventive Services Task Force. Ann Intern Med. 2004;140(10):822-835.

22. Scheckel MM, Nelson KA. An interpretive study of nursing students' experiences of caring for suicidal persons. J Prof Nurs. 2014;30(5): 426-435.

23. Happell B, Platania-Phung C. Mental health issues within the general health care system: the challenge for nursing education in Australia. Nurse Educ Today. 2005;25(6):465-471.
24. Bostwick JM, Rackley S. Addressing suicidality in primary care settings. Curr Psychiatry Rep. 2012;14(4):353-359.

25. Graham RD, Rudd MD, Bryan CJ. Primary care providers' views regarding assessing and treating suicidal patients. Suicide Life Threat Behav. 2011;41(6):614-623.

26. Prince A, Nelson K. Educational needs of practice nurses in mental health. J Prim Health Care. 2011;3(2):142-149.

27. Larkin GL, Claassen CA, Emond JA, Pelletier AJ, Camargo CA. Trends in US emergency department visits for mental health conditions, 1992 to 2001. Psychiatr Serv. 2005;56:671-677.

28. Allen MH, Abar BW, McCormick M, et al. Screening for suicidal ideation and attempts among emergency department medical patients: instrument and results from the Psychiatric Emergency Research Collaboration. Suicide Life Threat Behav. 2013;43(3):313-323.

29. Ross J, Darke S, Kelly E, Hetherington K. Suicide risk assessment practices: a national survey of generalist drug and alcohol residential rehabilitation services. Drug Alcohol Rev. 2012;31(6):790-796.

30. Ronquillo L, Minassian A, Vilke G, Wilson M. Literature-based recommendations for suicide assessment in the emergency department: a review. J Emerg Med. 2012;43(5):836-842.

31. Stuber J, Quinett P. Making the Case for Primary Care and Mandated Suicide Prevention Education. QPR Institute; 2013. Available from: http://www.qprinstitute.com/pdfs/PCP\%20SLTB $\% 20$ Word\%20F_ SLTB9_24.pdf. Accessed December 13, 2014.

32. Melton BB, Coverdale JH. What do we teach psychiatric residents about suicide? A national survey of chief residents. Acad Psychiatry. 2009;33(1):47-50.

33. Aflague JM, Ferszt GG. Suicide assessment by psychiatric nurses: a phenomenographic study. Issues Ment Health Nurs. 2010;31(4): 248-256.

34. Silverman M, Berman A. Training for suicide risk assessment and suicide risk formulation. Acad Psychiatry. 2014;38(5):526-537.

35. Provan KG, Veazie MA, Teufel-Shone NI, Huddleston C. Network analysis as a tool for assessing and building community capacity for provision of chronic disease services. Health Promot Pract. 2004;5(2): 174-181.

36. Brown GK. A Review of Suicide Assessment Measures for Intervention Research with Adults and Older Adults; 2000. Available from: http:// ruralccp.org/lyra-data/storage/asset/brown-nd-27cb.pdf. Accessed December 13, 2014.

37. Jobes DA, Eryman JR, Yufit RI. How clinicians assess suicide risk in adolescents and adults. Crisis Interv. 1995;2:1-12.

38. Posner K, Brown GK, Stanley B, et al. The Columbia-Suicide Severity Rating Scale: initial validity and internal consistency findings from three multisite studies with adolescents and adults. Am J Psychiatry. 2011;168:1266-1277.

39. Beck AT, Steer RA, Ranieri WF. Scale for suicidal ideation: psychometric properties of a self-report version. J Clin Psychol. 1988;44:499-505.

40. Beck AT, Steer RA. Manual for Beck Hopelessness Scale. San Antonio, TX: Psychological Corporation; 1988.

41. Linehan MM, Goodstein JL, Nielsen SL, Chiles JA. Reasons for staying alive when you are thinking of killing yourself: the reasons for living inventory. J Consult Clin Psychol. 1983;51:276-286.

42. Simon RI. Suicide risk assessment. In: Simon RI, editor. Assessing and Managing Suicide Risk-Guidelines for Clinically Based Risk Management. Washington, DC: American Psychiatric Press; 2004:25-60.

43. Range LM, Campbell C, Kovac SH, et al. No-suicide contracts: an overview and recommendations. Death Stud. 2002;26:51-74.

44. Drew BL. No-suicide contracts to prevent suicidal behavior in inpatient psychiatric settings. J Am Psychiatric Nurses Assoc. 1999;5:23-28.

45. Rudd MD, Mandrusiak M, Joiner TE. The case against no-suicide contracts: the commitment to treatment statement as a practice alternative. J Clin Psychol. 2006;62:243-251.

46. Kelly KT, Knudson MP. Are no-suicide contracts effective in preventing suicide in suicidal patients seen by primary care physicians? Arch Fam Med. 2000;9:1119-1121. 
47. Stanford EJ, Goetz RR, Bloom JD. The no-harm contract in the emergency assessment of suicidal risk. J Clin Psychiatry. 1994;55: 344-348.

48. Stanley B, Brown GK. Safety planning intervention: a brief intervention to mitigate suicide risk. Cognit Behav Pract. 2012;19:256-264.

49. Suicide Prevention Resource Center. Best Practices Registry; 2014. Available from: http://www.sprc.org/bpr/section-III/safetyplan-treatment-manual-reduce-suicide-risk-veteran-version. Accessed December 13, 2014.
50. Stanley B, Brown GK; in collaboration with Karlin B, Kemp JE, VonBergen HA. Safety Plan Treatment Manual to Reduce Suicide Risk: Veteran Version. Washington, DC: US Department of Veterans Affairs; 2008. Available from: http://www.mentalhealth.va.gov/docs/ VA_Safety_planning_manual.pdf. Accessed December 13, 2014.

\section{Publish your work in this journal}

The Journal of Multidisciplinary Healthcare is an international, peerreviewed open-access journal that aims to represent and publish research in healthcare areas delivered by practitioners of different disciplines. This includes studies and reviews conducted by multidisciplinary teams as well as research which evaluates the results or conduct of such teams or healthcare processes in general. The journal covers a wide range of areas and welcomes submissions from practitioners at all levels, from all over the world. The manuscript management system is completely online and includes a very quick and fair peer-review system. Visit http://www.dovepress.com/testimonials.php to read real quotes from published authors.

Submit your manuscript here: http://www.dovepress.com/journal-of-multidisciplinary-healthcare-journal 